Sri Lanka Journal of

Marketing

University of Kelaniya-Sri Lanka

\title{
How Brands opt Social Media Influencers for Influencer Marketing on Instagram: A Study on Sri Lankan Beauty \& Personal Care Brands
}

\begin{tabular}{|c|}
\hline Lakmal K.G.P. \\
plakmal95@gmail.com \\
Hettiarachchi H.A.H. \\
Senior Lecturer, University Kelaniya, Sri Lanka \\
harshaka@kln.ac.lk \\
Anuranga B.K.H.D. \\
Lecturer, University Kelaniya, Sri Lanka \\
dulip@kln.ac.lk
\end{tabular}

\section{ABSTRACT}

Prominent studies revealed that building the right relationship with the right social media influencer is one of the biggest challenges in influencer marketing. This study mainly aimed at exploring how Sri Lankan beauty and personal care brands opt social media influencers for their influencer marketing campaigns on Instagram. To fulfill the purpose of the study, the study adopted qualitative research approach based on semi-structured interviews to collect responses. The respondents were the personnel responsible for supervising influencer marketing campaigns of beauty and personal care brands in Sri Lanka. The study adopted thematic analysis to perform the analysis of the study and revealed that Sri Lankan beauty and personal care brands opt social media (Instagram) influencers based on top four "REAL" qualities, namely: Relatedness, Engagement, Authenticity and Loyalty. Moreover, researchers discovered the main reasons for choosing social media influencers by Sri Lankan beauty and personal care brands. In addition, study found that the same brands were not much interested in checking the demographic details when selecting social media influencers.

Keywords: Influencer Marketing, Instagram, Social Media, Social Media Influencer 


\section{INTRODUCTION}

Influencer marketing has become a novel approach for marketing. It is rapidly growing as it attempts to promote products/services and increase brand awareness through content spread by social media influencers (SMIs) (Carter, 2016). Instagram is one of the fastest growing social media platform which has more than 800 million active users worldwide (Leibowitz, 2019) and the most prominent influencer marketing channel over the years with enormous growth of SMIs (Bailis, 2019).

According to Amarasinghe (2019), considerable amount of SMIs on Instagram became influencers by merely buying fake followers and fake engagements through third party online tools. Thus, it is questionable whether these kind of SMIs have the ability to generate a true influence for a brand (Amarasinghe, 2019). Even though it is attractive for a company to hire an influencer with thousands of followers/audience on Instagram to promote the brand, if majority of influencer's followers are fake and irrelevant to the brand, then that investment is a waste of money (Gabriel, 2018). In the same way, Rodrigo (2018) claimed as there is a rising phenomenon of fake followers and fake engagement bots on Instagram, hence brands should be more diligent before choosing an influencer. Further, sometimes it could be observed that SMIs are promoting products and services on Instagram that are not matching with their profile.

Partnering with right SMI is the key factor for the success of influencer marketing (Radey, 2015). Nevertheless, collaborating with the right SMI is the biggest challenge in influencer marketing (eMarketer, 2015; Radey, 2015) as they have the ability to make or break the brand (7twelve Media, 2016). Therefore, building right relationship with the right SMI is timely important for brands. Sharma (2016) stated the importance of selecting relevant influencers who fit the brand as SMIs are a kind of third party endorsers who shape consumer attitudes (Freberg, Graham, McGaughey, \& Freberg, Who are the social media influencers? A study of public perceptions of personality, 2011). According to Veirman, Cauberghe, and Hudders (2017), when finding the right influencer, it is important to identify whether the influencer identity has an impact over buying decisions taken by consumers.

Researchers observed that there is a dearth of evidence on how Sri Lankan brands opt SMIs' for influencer marketing. Therefore, this study mainly intended to explore what qualities Sri Lankan beauty and personal care brands consider when selecting SMIs for influencer marketing on Instagram. 


\section{LITERATURE REVIEW}

\subsection{Social Media Influencers}

As a marketing communication strategy, celebrity endorsement plays a vital role in building a promising brand reputation (Lim, Radzol, Cheah, \& Wong, 2017). It uses well-regarded celebrities: such as actors/actresses, musicians, models, etc. to promote the brand (McKelvey, 2015). With the rise of social media channels, consumers are no longer exposed only to such traditional celebrities and are now influenced by "Social Media Influencers" (SMIs) who became famous via social media (Nouri, 2018). Abidin (2016) recognized SMIs as accumulators of large followers on social media by visualizing their personal lifestyles and engaging with their followers. Khamis, Ang and Welling (2017) stated that SMIs are also known as "Social Media Celebrities" or "Micro Celebrities". They make a kind of celebrity capital through claiming much attention and creating a trustworthy personal brand (Hearn \& Schoenhoff, 2015). SMIs are the key members of social groups in social media who can influence the other members in the same groups (Djafarova \& Rushworth, 2017). Rogers (1983) identified the one who holds a larger influence on others as an Opinion Leader. Therefore, SMIs act as opinion leaders in their communities.

\subsection{Influencer Marketing}

Due to the growth of social media acceptance, SMIs also have been increasingly emerged. As a result, these so called SMIs became a channel for marketing and it is labelled as "Influencer Marketing" (Freberg, Graham, McGaughey, \& Freberg, Who are the social media influencers? A study of public perceptions of personality, 2011). As these SMIs are able to reach large audience, marketers wish to collaborate with them by creating mutually beneficial relationships (Mudadeniya, 2018). According to him, influencer marketing is concerned with collaborating with SMIs who possess key audience in social media platforms to shape the consumer's opinion on brands. Influencer marketing works as a medium to get the brand's message to the potential customers. Therefore, brands collaborate with SMIs who eventually spread the brand's message to their followers. The essence of influencer marketing is determined by the relationship exists between the SMI and his/her followers. Loyal followers identify the influencers as close friends if they feel they are related each other through life styles, demographics and consumption preferences.

In influencer marketing, branded content either appears on the influencer's social media channel or on company's social media channels along with influencer's identity. While comparing with other marketing communication strategies, influencer marketing gives higher ROI and most of companies who involve in influencer marketing believe it as an effective tactic (Nielsen Catalina Solutions, 2016). Influencer marketing is not only limited to a simple endorsement given by influencers. It uses many 
tactics with the collaboration of influencers such as brand ambassadorship, brand mentions, product reviews, event coverage and sponsored content (Krasniak, 2016). Influencer marketing can happen in the context of both earned and paid media. It becomes earned when that influence happens organically without paying for it (Myhrman, 2019). Further, she emphasized that earned influence appears to be trustworthy as it is not sponsored. When brands pay influencers to promote their products or services, it becomes paid media and it is the most common form of influencer marketing.

\subsection{Influencer Marketing on Instagram}

According to Krasniak (2016), the most popular social media platform that marketers use to do influencer marketing is Instagram. It is one of the fastest growing social media platform which has more than 800 million active users and 1 million advertisers worldwide (Leibowitz, 2019). Presently, Instagram usage is increasing as a social media marketing tool (Stelzner, 2016) and it is the most often used platform to follow brands (Phua, Jin, \& Kim, 2017). Although there are number of channels to run influencer marketing campaigns, the newest marketing spectacle is promoting brands through Instagram (Enberg, 2018). According to Bailis (2019), Instagram has become the most prominent influencer marketing channel over years with the enormous growth of sponsored posts. Instagram influencer marketing surfaces when a brand uses a SMI who is on Instagram to spread a marketing message to his/her audience/followers (Haran, 2019).

Most of SMIs use Instagram for influencer marketing as it is a convenient platform to post visual story telling content and spread the brand by directly tagging them (Glucksman, The Rise of Social Media Influencer Marketing on Lifestyle Branding: A Case Study of Lucie Fink, 2017). Tagging brands let potential consumers to directly go and see the particular product or service. As Chen (2020) stated, 83\% of Instagram users discover new products or services via Instagram, thus it is an effective medium for businesses to reach out customers. Out of $69 \%$ of companies have planned to invest more on Instagram influencer marketing (Bailis, 2019).

\subsection{Selecting the Right Social Media Influencer}

According to Amarasinghe (2019), most of SMIs call themselves as influencers by accumulating larger follower base either organically or artificially. Further, he claims that there is a rising situation of becoming SMIs artificially as it can be achieved by the support of some third-party online tools (Rodrigo, 2018). Such platforms are equipped with programmed computer bots which allow them to buy fake social media (Instagram) followers in larger amounts. Similarly, paid services are available with the ability of generating likes, comments and engagements from genuine social media (Instagram) accounts (Gabriel, 2018). Therefore, becoming a SMI is easier than before. However, there is a question as to whether these SMIs have the ability to generate a true influence for a brand (Amarasinghe, 2019). 
Not everyone can be a genuine SMI just because of accumulating a larger follower base (Rodrigo, 2018; Amarasinghe, 2019). Radey (2015) also claimed that true influence is not a matter of larger social media followers as they can easily be bought. Veirman, Cauberghe and Hudders (2017) suggested, before collaborating with SMIs, it is important for brands to consider the topics that the SMIs talk and their followers' interests rather than just looking at the size of follower base. Therefore, it can be argued that the true SMI is someone who is beyond of having a larger follower base. Conforming with aforesaid assertion, Wong (2014) suggested below formula which could be used to evaluate SMIs.

The Power of SMI = Audience Reach (Number of Followers) $\mathrm{x}$ Brand Affinity (Expertise \& Credibility) x Strength of Relationship with followers (Engagement Rate).

Hamann (2014) suggested five measures to evaluate when a brand identify its potential SMIs. They can be listed as Relevance, Reach, Engagement, Authenticity and Frequency. Relevance is the level of fit between SMI and the brand. Reach is how far a brand's message travels within the community of SMI. In other words, how many followers see the influencer's message. Engagement reflects how interactive influencer's audience with content that influencer post, which is measured by the likes, comments and shares of the audience. Frequency is how often SMI post content on his/her social media channel. Authenticity refers to how genuine the SMI behave within his/her community and relatable with his/her followers.

Solis and Webber (2012) stated that starting with a desired end goal that is to be achieved through influencer marketing helps to select the most effective SMI. Thus, a brand should align its SMI with a specific measurable end goal. Brown and Fiorella (2013) argued that brands must collaborate with SMIs who can take potential consumers to the next stages of their purchase life cycle. Importantly, Brown and Fiorella (2013) proposed "The Influencer Filter" to ensure that brands select the right SMI. This model consists with four factors namely: Demographics (audience's age, gender and location, etc.), Time Scale (time period that campaign should run), Platform (channel that suits best to reach target audience) and Reaction History (how customers engaged with the influencer's content). They asserted that brands should evaluate these factors before picking up a prospective SMI. Apparently, researchers claim that there is lack of empirical validation even though many criteria being proposed regrading evaluation of SMIs.

\section{METHODOLOGY}

To achieve the study's aim, i.e. exploring how brands select SMIs for their influencer marketing, researchers are in the opinion that investigation and construction of knowledge to be based on social constructivism as the individuals: brands, construct the reality in the phenomenon. Responsible personnel from the brands who execute influencer marketing campaigns are the group of individuals 
responsible for creating the reality. Thus, social constructivism was the suitable philosophy for this study. The interpretivism nature of social constructivism study leads to develop new understanding about the phenomenon (Saunders, Lewis, \& Thornhill, 2009). Considering the purpose of this study, an exploratory method was used to investigate. Exploratory method enables to find new insights in a certain phenomenon and to clarify the precise nature of the problem (Saunders et al., 2009).

This study adopted a qualitative approach, aiming to achieve deeper understanding as well as discover new insights about the study context. Also, qualitative approach helps to enrich researchers' opinions and motives about how Sri Lankan brands select SMIs for their influencer marketing. This research was a cross-sectional study and Sri Lankan beauty and personal care brands were the unit of analysis. Beauty and personal care industry is globally leading the way in connecting with customers and building trust through influencer marketing (Gerdeman, 2019; Gilliland, 2018; McKeon, 2018).

Purposive sampling was the selected sampling method for this study, enabling researchers to use their judgment to select most appropriate cases which suited best to answer the research questions. As the logic of purposive sampling for selecting samples is dependable on research questions and objectives, researchers identified relevant criterions; the potential beauty and personal care brands to be originally Sri Lankan, to have a presence in Instagram and execute influencer marketing on Instagram via SMIs. The researchers determined sample size when data are at saturation: respondents giving similar responses for the same question as the moving forward with interviews. In fact, researchers continued gathering responses until the extra responses provided any new insights.

As this research was qualitative and exploratory in nature, researchers conducted semi-structured interviews to collect responses. The researchers conducted one-to-one interviews to collect data from respondents who oversee and execute Instagram influencer marketing at beauty and personal care brands in Sri Lanka. The study performed thematic analysis to analyse the responses gathered from five respondents. By performing the thematic analysis, researchers were able to find patterns within the respondents' views regarding how they choose SMIs for influencer marketing campaigns on Instagram.

As Guest, MacQueen, and Namey (2012) claimed, gathered responses should be reorganized, sorted and condensed in a way that researcher can draw precise conclusions. Hence, researchers transcribed all the conversations into transcripts which were in a similar format. Afterwards, categorizing was conducted by transforming all the transcripts into another format which helped researchers to find meaningful connections within the responses collected. Finally, the categorized responses were presented as the empirical findings.

This study was able to establish trustworthiness via maintaining credibility and transferability. Credibility of a study is established when researcher measures what is actually intended to measure by the study (Shenton, 2004). In this study, researchers adopted the member checking method to establish the credibility. In fact, respondents were asked to read the transcripts of the respective interview to 
check the compatibility with what they intended to mention. Transferability is the extent to which the findings of the study can be applied in other situations (Korstjens \& Moser, 2018). In this study, researchers were able to provide more detailed description on how Sri Lankan beauty and personal care brands select SMIs for influencer marketing on Instagram as well as a detailed description about the adopted research process.

As the code of conduct, this study followed the ethical guidelines proposed by the Market Research Society (2014). Thus, affirmed that the study was not harmful for anyone and did not commit any unethical violations. All respondents were contacted through emails and requested for an interview. The responses collected during the interviews were used in an anonymous way within the study to protect the respondents' confidentiality. Every respondent was encouraged to ask questions: during the interview, before the interview and after the interview.

\section{FINDINGS}

\subsection{Reasons for Using SMIs}

Respondents pointed out different reasons regarding why beauty and personal care brands use SMIs. Most of them use SMIs to reach a bigger audience and increase the brand awareness. Some respondents mentioned that they use SMIs to increase the followers in their Instagram profiles. Almost every respondent believed that SMIs help them to reach their potential customers and could convince for sales conversion.

R1 emphasized that he uses SMIs to reach a bigger audience and increase brand awareness.

"One thing is audience. When we have an Instagram page, we have only $1 \mathrm{k}$ followers. But influencers they have minimum $10 \mathrm{k}$ followers. So, they have a big audience. When they post a review, their $10 \mathrm{k}$ followers will see that, so then our brand will be reaching a little bit more. So, we need influencers"

R3 highlighted that she uses SMIs as a best way to go towards the public as she believes that followers are having a trust on SMIs. Further, she stated that she wanted to increase the number of Instagram followers of her brand profile.

“(...) everybody knows them, they trust them, and they believe in everything what they say. That's why I am always using influencers as a best way to go towards the public"

“(...) when I did with my main goal was to increase my followers and it worked".

R4 stated that they use SMIs as a medium to reach potential customers, thus believed that the sales could be further increased. 
“(...) we always focus on something that directly goes to the customer and make them to buy our products. So, we focus certain influencers that have the right amount of fan base around them"

Lou and Yuan (2019) acclaimed that brands invest in influencer marketing aim to grow their audience, boost brand awareness and consequently expect to drive sales. They emphasized that influencer generated posts on brands can positively affect followers' trust, which in turn affects their purchase intentions.

\subsection{Opting SMIs}

Researchers found that Sri Lankan beauty and personal care brands follow two steps namely (1) discovering and (2) evaluation and selection when opting SMIs.

\subsection{Discovering}

Respondents described how they find SMIs for their brands. Majority of respondents mentioned that they find SMIs via Instagram hashtags. Besides, some respondents stated that they get requests from SMIs to collaborate.

R1 and R2 highlighted that Instagram hashtags are helpful when finding SMIs who are interested on beauty and personal care.

"Instagram is helpful in there. I am using hashtags for my kind of products. It will show us these are the people you may like to follow. So, when I spend around 30 minutes on Instagram, I can find an influencer"

"I use certain hashtags related to my products. When I type those on my Instagram it helps me find influencers who follow same tags. That's one of way that I look"

R3 mentioned that she usually doesn't spend much time to find SMIs as they pop-up in her Instagram feed due to hashtags.

"I am not going out looking influencers. When she pops up on my feed, I look into her. I check into her"

$\mathrm{R} 2$ and R1 stated that they receive collaboration requests from local and foreign SMIs.

"We actually get a lot of requests from influencers that they want to collaborate with us"

"People reach me and ask can I review your product? So, I just check them. Even foreign people will ask" 
Bashari and Fazl-Ersi (2020) acclaimed that hashtags play a significant role in distinguishing influential posts from non-influential posts. Zote (2020) emphasized the use of hashtags as a key source for brands to discover potential SMIs in Instagram. Further, Audrezet, Kerviler and Moulard (2018) indicated that SMIs used to reach and request the brands to collaborate.

\subsection{Evaluation and Selection}

Respondents described how they evaluate and select SMIs. Thus, researchers identified top four (04) qualities that beauty and personal care brands usually expect from the SMIs. They are Relatedness (R), Engagement (E), Authenticity (A), and Loyalty (L). Researchers acronymed them as "REAL" qualities.

\subsection{Relatedness}

Majority stated they look at the relatedness of SMIs to their respective brands and clientele.

R1 and R3 emphasized that they don't consider SMIs who are interested on areas other than beauty and personal care.

"There are foods bloggers, there are beauty bloggers, and there are travel bloggers. I don't give my products to travel bloggers or food bloggers. Because, they are completely different"

"Let's assume someone who is doing food blogging. I can't ask her even she has 100k followers. I cannot ask her to promote my brand"

Similarly, R2 emphasized that she is very keen on the compatibility between brand and SMI.

"When we use it, we make sure they actually go hand in hand with our brand. We just don't use any kind of influencers"

Besides, R4 claimed that they check the related enthusiasm and passion of SMIs regarding the beauty and personal care.

"Actually expertise. She should be a beauty educator and one who is interested in this kind of stuff which means beauty products"

R5 added that alignment between the lifestyle of SMI and the brand is adequate to collaborate.

"When somebody lives according to a lifestyle that my brand wants, I mainly go for that"

Breves, Liebers, ABT and Kunze (2019) affirmed the importance of selecting a SMI who is compatible with the brand. Carter (2016) expressed that organizations now look at passionate and expert SMIs to promote related products and services. It is conceivable that SMI's expertise in specific area makes him/her qualified to promote related brands effectively (Lou \& Yuan, 2019). 


\subsection{Engagement}

Most of the respondents were used to evaluate and select SMIs based on their profile insights. Mainly, they used to observe user reactions/engagements (such as likes and comments) in the influencer's profile.

R2 highlighted that she checks the ratio between the followers and the real engagement within SMI's profile.

"I just go for her profile and see how many likes and comments they just got. There should be at least like $10 \%$ likes. If they have $10 \mathrm{k}$ followers, the likes need to be at least 800 or 1000 "

Similarly, R3 conveyed that they consider the amount of post engagements of SMIs.

"Most important thing is engagement. I need to be able to see the likes on the picture because I can't see their personal activities. What we can see is how many people like their picture. If I see someone who has $2 k 3 k$ likes I straightly go for it"

R1 expressed that he chooses SMIs who are having better and positive post engagements.

"When I see around five to six posts in their profiles with good engagements that they have done in the past, then I would like to prefer them for our product"

Apparently, followers' engagement is higher on Instagram, thus brands tend to widely use Instagram influencers to promote their products and services (Feehan, 2019). Veirman, Cauberghe and Hudders (2017) stressed that brands should evaluate followers' engagement within SMIs to determine the ideal candidature.

\subsection{Authenticity}

Some respondents emphasized that SMI should be a genuine and trustworthy personality for his/her followers. In fact, he/she must show true colors, shouldn't cheat, shouldn't break promises and should spread honesty to his/her audience. Accordingly, SMI should be a believable source to the public.

R3 emphasized that she assesses whether the particular SMI shows his/her authentic life, i.e. showing his/her true appearance to the digital world.

“(...) she's not an average model, a dark skin girl. If you see her profile, she is not afraid to be who she is. She is showing it to everyone. I wanted to promote that it is ok to be a dark skin girl"

R2 stressed that authenticity of a SMI is the utmost concern for her to choose a SMI to represent her brand. 
"For me, the main thing would be authenticity"

“(...) so, I look at how credible their profiles are”

Further, R1 highlighted that SMI's genuineness is reflected in his/her posts. Hence, it is considered when selecting a potential SMI to promote the respective brand.

"They should be trustworthy. When we see their post, they should be genuine"

Trustworthiness is an important determinant in making Instagram SMIs more influential (Jin, Muqaddam, \& Ryu, 2019). In fact, the main reason why people follow SMIs is the presumed authenticity (Kádeková \& Holienčinová, 2018).

\subsection{Loyalty}

Some respondents mentioned that they expect to select a SMI who is loyal and honest to the brand and to the respective company. They firmly believe such committed SMIs consequently bring actual influence for the brand.

R4 highlighted that they are delighted to have SMIs who really care about the brand.

"When we gave some of our samples to her, she always came back with feedback and made own review videos. She did it because she was really concern about the product. When the influencer really loves the brand, we would love to connect with her because that's what we want"

R2 said that she had bad experiences with some SMIs who cheated on her. Therefore, she emphasized that SMIs should be trustful and rich with honesty.

"Other thing is trustworthiness because sometimes they only take the product and don't come back again”

Similar, R1 stated he seeks for SMIs who are reliable.

"They should be trustworthy. If I come to know that they are fake ones and taking money and doing nonsense, I am not going for them"

R1, R2 and R3 stated that they expect SMIs to be honest and unbiased.

"We give them a product and tell them, ok use this and give me an honest review"

"We give them products as giveaway. They will actually use it and they will give us their honest opinion. If they don't like something, they will tell us, if they like it, they will tell us"

"I want unbiased reviews. They will try my products and they will tell the truth" 
Driel and Dumitrica (2020) acclaimed that SMI should be transparent and honest when working with brands. Thus, favorable selection of SMI will be driven by the loyalty and credibility of SMIs towards brands.

\subsection{SMIs' Demographic Details}

Knowing SMI's demographic details and follower count were not specific and significant concerns for majority of respondents when selecting a SMI.

R3 agreed that she barely check SMI's demographic details and wouldn't rely on such details when selecting a SMI.

\section{“(...) But in term of checking demographics, I don't do it as much”}

R4 stated that follower count of a SMI is immaterial when choosing a potential SMI.

"Not really on the follower count. First, we see their profile if they really fit our brand. If influencer has 100k followers doesn't mean she is good at cosmetics"

R1 expressed that he doesn't even ask for the audience/follower details from SMIs.

"I don't ask influencer to provide the data. I know influencer would have the data behind the settings. They can see the activity, they can see the age, in which town they come from, men or women. They can see everything. But, I don't request such things from her"

Brands should look beyond just the number of followers to determine their ideal influencers as high numbers of followers do not necessarily evoke real brand influence (Veirman, Cauberghe, \& Hudders, 2017). Seemingly, some authors claim that influencer selection process should include consideration of the target audience's demographics (e.g., Brown \& Fiorella, 2013). However, researchers concluded that selected beauty and personal care brands were not interested on gauging the follower demographics when opting SMIs to represent their brands.

\section{CONCLUSION}

Influencer marketing has become the newest buzzword in the digital marketing spectrum. Over the recent years, influencer marketing has evolved rapidly and now become the fastest-growing online marketing channel as many brands started investing on influencer marketing. Nevertheless, selecting the right SMI is identified as an emerging challenge faced by the brands. In fact, partnering up with the right SMI is a catalyst to branding. There could be many reasons why brands incorporate influencer marketing. Researchers derived compelling reasons for Sri Lankan beauty and personal care brands to select SMIs for influencer marketing. Mainly, influencer marketing enables them to reach their targeted audience, boost brand awareness, and go for ultimate sales conversion. 
Working with the right influencer is the key to successful influencer marketing. This study also revealed how Sri Lankan beauty and personal care brands select SMIs. Respondents of the study expressed their different views on selecting SMIs for their influencer marketing campaigns on Instagram. Consequently, Sri Lankan beauty and personal care brands wish to select SMIs based on Relatedness, Engagement, Authenticity and Loyalty. Thus, researchers proposed a new model known as "REAL" representing aforesaid qualities. Therefore, it will provide a fundamental guidance to new brands who wish to successfully implement influencer marketing.

Further, the study discovered that Sri Lankan beauty and personal care brands were not interested on knowing the follower demographic details and follower count of SMIs when collaborating with them. Hence, researchers could accept the assertion made by previous authors (e.g., Amarasinghe, 2019; Rodrigo, 2018) who stated that everyone is not a true SMI just because he/she accumulate a larger follower base as followers can be easily bought. However, some authors (e.g., Brown \& Fiorella, 2013) argued that it is essential to check the demographics of the SMI's audience as it helps to identify the exact target audience that brand should focus. As there is a rising problem of buying fake followers, researchers are in an opinion that brands should be extra diligent and should check the demographics of SMI's followers.

In this study, researchers mainly discovered the key qualities that Sri Lankan beauty and personal brands expect when selecting SMIs. However, there is a rising situation of fake SMIs. Therefore, researchers suggest that every brand should be wise and use intelligent measures to evaluate SMIs. Moreover, researchers recommend brands to involve a systematic study to re-evaluate their existing SMI selection criterion. Researchers also noted that brands are now having the privilege of employing new technological tools and applications that could facilitate effective selection of SMIs. Further, it is suggested for future researchers to extend this study for other industries and other social media platforms to get a holistic view.

\section{REFERENCES}

[01]. 7twelve Media. (2016, April 13). How Social Media Influencers Can Make or Break Your Brand. Retrieved from Medium: https://medium.com/@7twelveTeam/how-social-mediainfluencers-can-make-or-break-your-brand-26219c2f50d6

[02]. Abidin, C. (2016). Visibility labour: Engaging with Influencers' fashion brands and \#OOTD advertorial campaigns on Instagram. Media International Australia, 161(1), 86-100. 
[03]. Amarasinghe, A. (2019, April 04). The Problem of Instagram Fakefluencers: Are they really capable to improve brands? Retrieved from Amisampath: https://www.amisampath.com/2019/04/the-problem-of-instagram-fakefluencers.html

[04]. Audrezet, A., Kerviler, G. D., \& Moulard, J. G. (2018). Authenticity under threat: When social media influencers need to go beyond self-presentation. Journal of Business Research.

[05]. Bailis, R. (2019, March 27). The State of Influencer Marketing: 10 Influencer Marketing Statistics to Inform Where You Invest. Retrieved from Bigcommerce: https://www.bigcommerce.com/blog/influencer-marketing-statistics/

[06]. Bashari, B., \& Fazl-Ersi, E. (2020). Influential post identification on Instagram through caption and hashtag analysis. Measurement and Control, 53(3-4), 409-415.

[07]. Breves, P. L., Liebers, N., ABT, M., \& Kunze, A. (2019). The Perceived Fit between Instagram Influencers and the Endorsed Brand: How Influencer-Brand Fit Affects Source Credibility and Persuasive Effectiveness. Journal of Advertising Research, 59(4), 440-454.

[08]. Brown, D., \& Fiorella, S. (2013). Influence Marketing: How to Create, Manage, and Measure Brand Influencers in Social Media Marketing. Que Publishing.

[09]. Carter, D. (2016). Hustle and Brand: The Sociotechnical Shaping of Influence. Social Media + Society, 2(3), 1-12.

[10]. Chen, J. (2020, May 06). Important Instagram stats you need to know for 2020. Retrieved from Sprout Social: https://sproutsocial.com/insights/instagram-stats/

[11]. Djafarova, E., \& Rushworth, C. (2017). Exploring the credibility of online celebrities' Instagram profiles in influencing the purchase decisions of young female users. Computers in Human Behavior, 68, 1-7.

[12]. Driel, L. V., \& Dumitrica, D. (2020). Selling brands while staying “Authentic”: The professionalization of Instagram influencers. Convergence: The International Journal of Research into New Media Technologies, 1-19.

[13]. eMarketer. (2015, July 09). Marketers Pair Up with Influencers — and It Works. Retrieved from eMarketer: https://www.emarketer.com/Article/Marketers-Pair-Up-with-InfluencersandWorks/1012709 
[14]. Enberg, J. (2018, July 17). Instagram Leads as a Global Platform for Influencer Marketing. Retrieved from eMarketer: https://www.emarketer.com/content/instagram-is-the-leadingplatform-for-influencer-marketing

[15]. Feehan, B. (2019, February 15). 2019 Social Media Industry Benchmark Report. Retrieved from Rival IQ: https://www.rivaliq.com/blog/2019-social-media-benchmark-report/\#title-allindustry

[16]. Freberg, K., Graham, K., McGaughey, K., \& Freberg, L. A. (2011). Who are the social media influencers? A study of public perceptions of personality. Public Relations Review, 37(1), 90-92.

[17]. Gabriel, T. (2018, May 23). Brands Are Still Being Fooled By Influencers With Fake Followers. Retrieved from Contently: https://contently.com/2018/05/23/fake-followersfooled-brands/

[18]. Gerdeman, D. (2019, December 13). How Influencers Are Making Over Beauty Marketing. Retrieved from Forbes: https://www.forbes.com/sites/hbsworkingknowledge/2019/12/13/how-influencers-aremaking-over-beauty-marketing/\#4672f3081203

[19]. Gilliland, N. (2018, June 6). How Beauty Brands Have Evolved Their Influencer Marketing. Retrieved from econsultancy: https://econsultancy.com/how-beauty-brands-have-evolvedtheir-influencer-marketing/

[20]. Glucksman, M. (2017). The Rise of Social Media Influencer Marketing on Lifestyle Branding: A Case Study of Lucie Fink. Elon Journal of Undergraduate Research in Communications, 8(2), 77-87.

[21]. Guest, G., MacQueen, K. M., \& Namey, E. E. (2012). Applied Thematic Analysis. Thousand Oaks, CA: SAGE Publications, Inc.

[22]. Hamann, H. (2014, December 11). 5 Tips for Finding the Right Social Influencers for Your Brand. Retrieved from Convince \& Convert: https://www.convinceandconvert.com/digitalmarketing/5-tips-for-finding-the-right-social-influencers-for-your-brand/

[23]. Haran, R. (2019, June 10). How to Do Instagram Influencer Marketing. Retrieved from Oberlo: https://www.oberlo.com/blog/instagram-influencer-marketing 
[24]. Hearn, A., \& Schoenhoff, S. (2015). From Celebrity to Influencer: Tracing the Diffusion of Celebrity Value across the Data Stream. In P. D. Marshall, \& S. Redmond (Eds.), A Companion to Celebrity (pp. 194-212). John Wiley \& Sons.

[25]. Jin, S. V., Muqaddam, A., \& Ryu, E. (2019). Instafamous and social media influencer marketing. Marketing Intelligence \& Planning, 37(5), 567-579.

[26]. Kádeková, Z., \& Holienčinová, M. (2018). Influencer marketing as a modern phenomenon creating a new frontier of virtual opportunities. Communication Today, 9(2), 90-105.

[27]. Khamis, S., Ang, L., \& Welling, R. (2017). Self-branding, 'micro-celebrity' and the rise of Social Media Influencers. Celebrity Studies, 8(2), 191-208.

[28]. Korstjens, I., \& Moser, A. (2018). Series: Practical guidance to qualitative research. Part 4: Trustworthiness and publishing. European Journal of General Practice, 24(1), 120-124.

[29]. Krasniak, M. (2016, November 24). Social Influencer Marketing on the Rise: New Research. Retrieved from Social Media Examiner: https://www.socialmediaexaminer.com/socialinfluencer-marketing-on-the-rise-new-research/

[30]. Leibowitz, B. (2019, December 09). Instagram vs Facebook: Which Can Boost Your Business More? Retrieved from DreamGrow: https://www.dreamgrow.com/instagramfacebook-advertising/

[31]. Lim, X. J., Radzol, A. B., Cheah, J., \& Wong, M. W. (2017). The Impact of Social Media Influencers on Purchase Intention and the Mediation Effect of Customer Attitude. Asian Journal of Business Research, 7(2), 19-36.

[32]. Lou, C., \& Yuan, S. (2019). Influencer Marketing: How Message Value and Credibility Affect Consumer Trust of Branded Content on Social Media. Journal of Interactive Advertising, 19(1), 58-73.

[33]. McKelvey, K. (2015). The Marketing of Fashion. In Textiles and Fashion (pp. 763-797). Newcastle upon Tyne: Woodhead Publishing.

[34]. McKeon, R. (2018, October 31). How Are Beauty Brands Evolving Their Influencer Marketing. Retrieved from Beauty Business Journal: https://beautybusinessjournal.com/howare-beauty-brands-evolving-their-influencer-marketing/ 
[35]. Mudadeniya, D. (2018, October 29). Influencer Marketing: Opening New Doors in Communication. Retrieved from Daily FT: http://www.ft.lk/columns/Influencer-marketingOpening-new-doors-in-communication/4-665588

[36]. Myhrman, H. (2019, April 03). This is The Difference Between Paid and Earned Influencer Marketing. Retrieved from Medium: https://medium.com/getflowboxblog/this-is-thedifference-between-paid-and-earned-influencer-marketing-8852901dcbce

[37]. Nielsen Catalina Solutions. (2016). Sales Effect Study: Influncer Marketing. TapInfluence. Retrieved from https://www.tapinfluence.com/tp_resource/nielsen-casestudy/?_ga=2.76667613.999522064.1594548976-2058079742.1594548976

[38]. Nouri, M. (2018). The Power of Influence: Traditional Celebrity vs Social Media Influencer. Pop Culture Intersections, 32.

[39]. Phua, J., Jin, S. V., \& Kim, J. (2017). Gratifications of using Facebook, Twitter, Instagram, or Snapchat to follow brands: The moderating effect of social comparison, trust, tie strength, and network homophily on brand identification, brand engagement, brand commitment and membership intention. Telematics and Informatics, 34(1), 412-424.

[40]. Radey, T. (2015, May 27). Influencer Marketing: Why Relevance Is More Important Than Vanity Metrics. Retrieved from PR 20/20: https://www.pr2020.com/blog/influencermarketing-why-relevance-is-more-important-than-vanity-metrics

[41]. Rodrigo, J. (2018, December 16). Fake Followers; The Bane of Influencer Marketing. Retrieved from The Morning: http://www.themorning.lk/brunch-page-4-disruptech-column-7/

[42]. Rogers, E. M. (1983). Diffusion of Innovations (3rd ed.). New York: Free Press.

[43]. Saunders, M., Lewis, P., \& Thornhill, A. (2009). Research Methods for Business Students. New York: Pearson.

[44]. Sharma, S. (2016, September 06). Beauty Under the Influence. Retrieved from Global Cosmetic Industry: https://www.gcimagazine.com/business/marketing/Beauty-Under-theInfluence-392484651.html

[45]. Shenton, A. K. (2004). Strategies for Ensuring Trustworthiness in Qualitative Research Projects. Education for Information, 22(2), 63-75. 
[46]. Solis, B., \& Webber, A. (2012). The Rise of Digital Influence: A "How-To" Guide for Businesses to Spark Desirable Effects and Outcomes Through Social Media Influence. Altimeter. Retrieved from https://www.slideshare.net/Altimeter/the-rise-of-digital-influence

[47]. Stelzner, M. (2016, May 24). 2016 Social Media Marketing Industry Report. Retrieved from Social Media Examiner: https://www.socialmediaexaminer.com/social-media-marketingindustry-report-2016/

[48]. The Market Research Society. (2014). Code of Conduct. Retrieved from The Market Research Society: https://www.mrs.org.uk/standards/code-of-conduct

[49]. Veirman, M. D., Cauberghe, V., \& Hudders, L. (2017). Marketing through Instagram influencers: the impact of number of followers and product divergence on brand attitude. International Journal of Advertising, 36(5), 798-828.

[50]. Wong, K. (2014, September 10). The Explosive Growth of Influencer Marketing And What It Means For You. Retrieved from Forbes: https://www.forbes.com/sites/kylewong/2014/09/10/the-explosive-growth-of-influencermarketing-and-what-it-means-for-you/\#4ce4f5bd52ac

[51]. Zote, J. (2020, May 05). How to Find and Reach Your Target Audience on Instagram. Retrieved from Sprout Social: https://sproutsocial.com/insights/instagram-target-audience/ 